\title{
Dynamics of shallow-water juvenile flatfish nursery grounds: application of the self-thinning rule
}

\author{
R. D. M. Nash ${ }^{1, *}$, A. J. Geffen ${ }^{2}$, M. T. Burrows ${ }^{3}$, R. N. Gibson ${ }^{3}$ \\ ${ }^{1}$ Institute of Marine Research, PB 1870 Nordnes, 5817 Bergen, Norway \\ ${ }^{2}$ Department of Biology, University of Bergen, PB 7800, 5020 Bergen, Norway \\ ${ }^{3}$ Dunstaffnage Marine Laboratory, PO Box 3, Oban, Argyll PA34 4AD, Scotland
}

\begin{abstract}
Annual development of density and mean weight of juvenile plaice Pleuronectes platessa was examined at 2 nursery grounds (Port Erin Bay, Isle of Man, Irish Sea and Admucknish Bay, Firth of Lorne, west coast of Scotland) over a number of years. In both cases there was evidence of 'self-thinning' in the populations when the density was high, although in Port Erin Bay the slope suggested a relationship different from the standard $-4 / 3$ rule proposed for animal populations. The site specific dynamic thinning lines (dynamic carrying capacities) were consistent with the dynamic thinning line $(-4 / 3$ rule) for both populations. The 2 nursery grounds were different, with growth rates and densities generally higher on the Ardmucknish Bay nursery ground compared with Port Erin Bay. Similarly, the estimated total biomass of plaice was higher in Ardmucknish Bay than Port Erin Bay, but there was considerable inter-annual variation. Maximum plaice biomass generally occurred from August to September for both sites. In Port Erin Bay this coincided with the maximum consumption rates. The size structure was described using the Gini coefficient $(G)$ and the timing of size structure development by the centre of gravity $(C G)$. The size structure of the populations differed and in both cases varied during the season in response to settlement and mortality. Over the study periods, population density was only occasionally high enough to reach the site specific self-thinning line. This suggests that these populations rarely approached the carrying capacity of the nursery grounds.
\end{abstract}

KEY WORDS: Flatfish · Nurseries $\cdot$ Self-thinning $\cdot$ Density $\cdot$ Plaice

\section{INTRODUCTION}

Settlement of newly metamorphosing plaice Pleuronectes platessa $\mathrm{L}$. onto nursery grounds occurs in pulses within a settlement period (Hyder \& Nash 1998). In general, large numbers of very small individuals $(14-17 \mathrm{~mm})$ arrive on nursery grounds in late spring and are subject to relatively high mortality (Beverton \& Iles 1992, Nash \& Geffen 2000). Through the following months individual biomass increases and simultaneously the density (ind. $\mathrm{m}^{-2}$ ) declines due to mortality. Individuals may also face space limitation for foraging (Steingrímsson \& Grant 1999) even if they are not necessarily territorial but simply 'site faithful' (Burrows et al. 2004). On occasion, high fish abundance and/or low prey density may impose a carrying capacity, i.e. a maximum density, on the population (Kashiwai 1995). The population response can be manifested as emigration (Goss-Custard et al. 2002) or an increase in mortality. The 'self-thinning rule' (Begon et al. 2006) has been used to describe the development of populations over time. This is manifested as a change in density as a consequence of an increase in mean weight (Begon et al. 1986, Elliott 1993, Grant 1993, Latto 1994, Fréchette \& Lefaivre 1995, Armstrong 1997, Steingrímsson \& Grant 1999).

The self-thinning rule has been applied to animal populations where individuals are in direct physical contact with each other, such as barnacle populations. Changes in mean size/biomass follow trajectories similar to plant populations, giving a general relationship between log density versus log mean weight with a 
slope of $-3 / 2$ (Hughes \& Griffiths 1988). Probably the more appropriate terminology for the relationship in animal populations is a dynamic thinning line (see Begon et al. 2006). Two thinning mechanisms that have been suggested for mobile organisms are competition for space and competition for food (Begon et al. 1986, Elliott 1993, Grant 1993, Latto 1994, Armstrong 1997, Steingrímsson \& Grant 1999). As an animal population develops over time, the mean body size increases and the density of the population declines through either death or emigration (Dunham et al. 2000), producing a dynamic thinning line with a general slope of $-4 / 3$ (Begon et al. 1986).

If space is limiting, the allometry of the territory sizes sets the maximum population density at each individual body size. This in turn sets the dynamic thinning relationship (Steingrímsson \& Grant 1999). As territorial individuals grow, they defend ever larger territories and consequently the density declines. In the case of salmonids, the reduction in density is probably caused by individuals moving to less favorable sites (Elliott 1986). There is no evidence for territoriality in plaice, thus the situation on nursery grounds is different. Space limitation for 'free ranging' individuals may be linked to foraging, but this has not been estimated for juvenile plaice on nursery grounds.

Competition for food can be expressed by the energetic equivalence hypothesis. This predicts that the slope of a dynamic thinning line is determined by the allometry of the metabolic requirements or food consumption, with the proviso that there is a constant amount of energy flowing through the population (Begon et al. 1986, Bohlin et al. 1994). Here self-thinning occurs because as the animals grow, fewer individuals can survive on a given amount of food. The general relationship applicable to many species is that resting metabolic rate is proportional to (body mass) ${ }^{\beta}$ where $\beta \approx 0.75$; however, this relationship should be determined for each species (Latto 1994). In the case of young plaice (total length $>60 \mathrm{~mm}$ ), $\beta$ is temperature dependent and ranges from 0.68 to 0.92 (Fonds et al. 1992). Population changes modeled directly from energetic principles produce a self-thinning slope between -1.1 and -1.5 . This compares favorably with both predicted and observed self-thinning lines (slope: $-3 / 2$ or -1.5 ) and dynamic thinning lines (slope: $-4 / 3$ or $-1.33)$.

Population size structure, and its relationship to population density and mortality rates (thinning), is less well studied in animal populations than in plant populations (Begon et al. 2006). The development of size structure may proceed differently under conditions with different resource limitations. In plant communities, the development of size heterogeneity and the inequality of biomass distribution among individuals can be expressed by the Gini coefficient, which is used as an indication of types of competition and selective mortality (Creed et al. 1996). However, this type of temporal analysis of the development of populations is less common in animal population studies, although well developed in parasitology (see Poulin \& Latham 2002), and it is rarely applied to marine fish (Geffen 1996). The size structure of the population and how this structure changes over time might be a more sensitive indicator of population responses.

Fish nursery grounds, especially shallow-water flatfish nursery grounds, have interesting population dynamics because they support annually renewed populations of fish, which often reach relatively high densities. For example, densities of $>6$ ind. $\mathrm{m}^{-2}$ have been measured on Scottish shores (Wennhage et al. 1997). The densities, growth rates, and mortality rates have been studied extensively, with long-term data sets for some locations (see Beverton \& Iles 1992). However, only rarely has the development of the nursery ground population been studied over the course of a single season and repeatedly over several seasons. We collected data on changes at 2 juvenile plaice nursery grounds to examine the relationship between density and mean biomass in the context of dynamic thinning lines. We evaluated the development of the population size structure in response to density changes over the season. We calculated the extent of population heterogeneity using the Gini coefficient to measure the distribution of biomass among individuals in the population. We also tested whether the centre of gravity measure (Gould et al. 1987), which was developed to measure changes in species diversity over geologic time, can be applied to quantify and compare differences in the timing of the development of population size structure. These analyses were then used for a general consideration of the relationship between dynamic thinning lines (the self-thinning rule), carrying capacity and the dynamics of the juvenile flatfish populations during the nursery ground phase.

\section{MATERIALS AND METHODS}

Field sampling. Population densities of juvenile plaice in Port Erin Bay $\left(54^{\circ} 5^{\prime} \mathrm{N}, 4^{\circ} 46^{\prime} \mathrm{W}\right.$; for map of location see Nash \& Geffen 2000) were estimated from 5 transects sampled (orthogonal to the shoreline) with a $1.5 \mathrm{~m}$ beam trawl between April and July and then a $2 \mathrm{~m}$ beam trawl between July and November. The $1.5 \mathrm{~m}$ beam trawl had $5 \mathrm{~mm}$ stretched mesh throughout and the $2 \mathrm{~m}$ beam trawl had $9 \mathrm{~mm}$ stretched mesh throughout. Both beam trawls were fitted with triple tickler chains. The gear was changed to accommodate the seasonal changes in fish size and to avoid net clog- 
ging from the accumulation of vegetation. Sampling occurred weekly (when weather permitted) between 1994 and 1999. Each transect was sampled once on each date. All captured fish were counted, measured (total length) to the nearest $1 \mathrm{~mm}$ below and weighed (total wet weight) to the nearest $0.1 \mathrm{~g}$. The density of plaice was calculated for each transect separately (Nash \& Geffen 2000). An average efficiency of the nets was assumed to be $25 \%$ for the whole time period (see Edwards \& Steele 1968). Daily sea surface temperatures in Port Erin Bay were measured at the Port Erin Marine Laboratory (PEML) and supplied by T. Shammon of the Isle of Man Government.

Population densities were also estimated in Ardmucknish Bay $\left(56^{\circ} 30^{\prime} \mathrm{N}, 5^{\circ} 20^{\prime} \mathrm{W}\right)$ near Oban in the west of Scotland (for map of location see Gibson et al. 1993). Samples were taken every 2 wk from midMarch to September and monthly until November for 3 yr between 1995 and 1997. The sampling technique was adopted to provide continuity with an earlier sampling scheme in the same location from 1986 to 1989 (Gibson et al. 1993). Hauls were made with a $2 \mathrm{~m}$ beam trawl with a $0.5 \mathrm{~cm}$ mesh and $6 \mathrm{~mm}$ cod end. Each haul was perpendicular to the shoreline, starting on the beach and ending at $5 \mathrm{~m}$ depth and taking about 4 to $5 \mathrm{~min}$ to cover the distance of 100 to $200 \mathrm{~m}$. The depth range ensured that the entire population of 0-group plaice was sampled, and that the numbers were unbiased by the depth distribution of the animals. Three hauls in Ardmucknish Bay were taken on each sampling date. Every juvenile plaice was measured to the nearest $1 \mathrm{~mm}$ below, except where high catches required sub-sampling. Mean length per sampling date was calculated and converted to mean weight per sampling date using the following relationship: $W=0.8 \times L^{3}$, where $W$ is in $\mathrm{g}$ and $L$ is in $\mathrm{cm}$, based on samples from this location. In this case, catches were not corrected for gear efficiency; therefore, real densities may be higher.

Calculation of dynamic thinning lines. The data collected on each sampling date was used to calculate the relationship between mean weight and population density for the 2 nursery grounds. The trajectories of these relationships were examined and compared to the theoretical dynamic thinning line which has a slope of $-4 / 3(-1.33)$. On plaice nursery grounds the density and mean weight of individuals should increase in the early part of the season as fish settle and fish grow (Fig. 1). Initially, density should increase through immigration, accompanied by a relatively slow increase in mean weight because of the new smaller individuals. Once settlement is completed, density should decrease due to nursery ground mortalities, and mean weight should increase at a faster rate. If the density reaches the carrying capacity of the nursery ground and if these plaice populations exhibit dynamic thinning, then the relationship between density and mean weight during that period should have a slope of ca. $-4 / 3$. During autumn, at a time that is probably nursery ground dependent, emigration begins and the fish density declines faster. Mean weight may decrease, and apparent growth rate also slows, because the larger individuals move off the nursery grounds, leaving the smaller individuals behind.

The values of mean weight $(\log W, \mathrm{~g})$ and population density $\left(\log N\right.$, ind. $\mathrm{m}^{-2}$ ) for each sampling date were plotted chronologically for each year and each site separately. Dynamic thinning lines were calculated for each year between the time period when the density was at maximum (usually June/July each year) and when the mean weight reached a maximum (usually September/October) (see Table 3). In general, these values chronologically followed a straight line (Fig. 1). Differences between lines were compared by ANCOVA. Site specific dynamic thinning lines (expected dynamic carrying capacities) were estimated for each site. The objective was to characterise the relationship between the maximum density and its associated mean weight over all years. In the case of Port Erin Bay the 3 highest mean densities in each 0.5 ind. $\mathrm{m}^{-2}$ 'bin' were regressed with their corresponding mean weights. In the case of Ardmucknish Bay, there was a series of

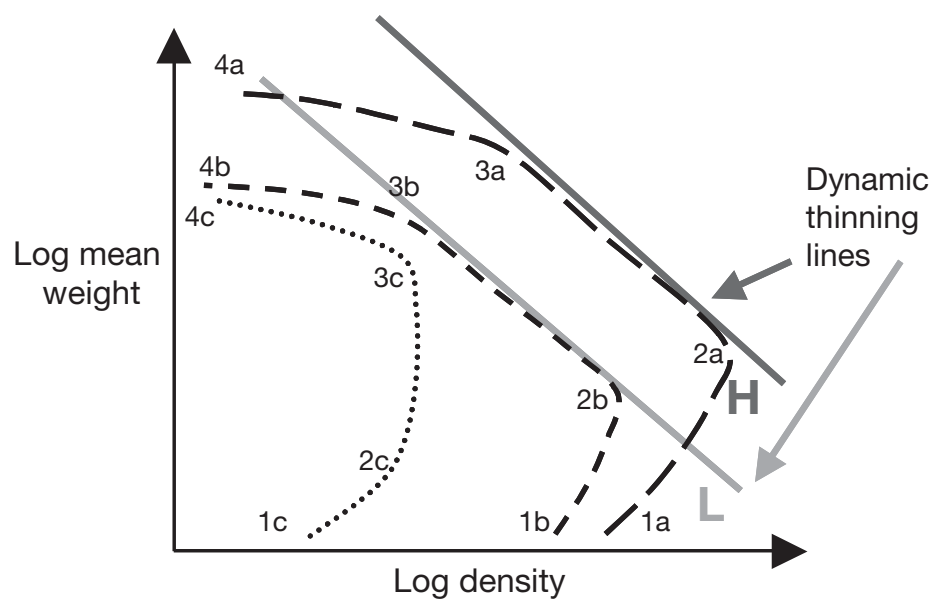

Fig. 1. Pleuronectes platessa. Population trajectories for juvenile plaice populations on nursery grounds with different carrying capacities or where settlement varies between years. $\mathrm{H}$ and $\mathrm{L}$ are high and low carrying capacity dynamic thinning lines. Trajectories of density vs. mean weight are given by dotted and dashed lines. Three population trajectories are given: a (large dashed line) and b (small dashed line) for high settlement years and c (dotted line) for a low settlement year. 1: start of settlement or supply of new young plaice (April/May); 2: completion of settlement (May/July); 3: onset of emigration of young plaice off the nursery grounds (August/September); 4: overwintering population left in the shallow water of the nursery grounds (October/February). Models based on Begon et al. (2006) 
sampling dates with much higher densities (most occurring in 1986) which provided the higher limits for the density/mean weight relationship.

Calculation of population parameters. Instantaneous mortality rates were estimated for both sites as the reduction in abundance over time for the period July to October (see Nash \& Geffen 2000). Growth rates (length and weight) were estimated by linear regression as the increase in mean length or weight over time. Daily food consumption (DFC) was calculated in order to evaluate the population level patterns during the season. DFC was estimated in 2 ways, based on Fonds et al. (1992). The first method estimated maximum daily food consumption $\left(C_{\max }\right)$ as Ash Free Dry Weights (AFDW) using the formula:

$$
C_{\max }=A W^{B}
$$

where the temperature dependent coefficients $A$ and $B$ are given in Table 4 of Fonds et al. (1992). Wet weight of plaice was converted to AFDW using the formula:

$$
\% A F D W=33.1-15.5 / K
$$

where condition factor $K=W / L^{3} \times 100$; for the population this was estimated using the mean weight $(W, g)$ and the mean length $(L, \mathrm{~cm})$ on the sampling date.

The second method estimated the daily wet weight consumption $(d F)$ using the formula:

$$
d F=0.32 \times W^{0.74} \times \mathrm{e}^{0.2 \mathrm{~T}}
$$

where $T=$ temperature $\left({ }^{\circ} \mathrm{C}\right)$.

The temporal development of population size structure on the 2 nursery grounds was visualized with 2 metrics, the centre of gravity $(C G)$ and the Gini coefficient $(G)$. $C G$ describes how the size diversity of the population develops over time, and $G$ describes the evenness of a population in terms of the size frequency distribution across the total range of sizes.

Non-linear changes in size variation over time were examined by calculating $C G$ (Gould et al. 1987) based on the coefficient of variation ( $\mathrm{CV}=\mathrm{SD} / \mathrm{mean})$ of the mean length. $C G$ is defined as the relative position in time of a population's mean diversity and can be applied to any measured variable (Gould 1988):

$$
C G=\frac{\sum_{i=1}^{n} N_{i} t_{i}}{\sum_{i=1}^{n} N_{i}}
$$

where $N$ is the diversity in sizes (represented by the $\mathrm{CV}$ of length distribution) of the population in the $i$ th time period, and $t$ is the proportion of the total time period elapsed. CG ranges between 0 and 1, and in this case values closer to 0 indicate that the size variation within the population was larger earlier in the season (April to June) and values closer to 1 indicate that the population size structure contained the widest variation later in the season (June to November). $C G$ was calculated for the period between settlement and emigration (1 April to 1 November) in each year, during which time the sampling intervals were comparable (bi-weekly or monthly). The comparisons of $C G$ between years and between beaches were unbiased because the time period was standardized and sampling frequencies were similar (Foote 1991). The values of $C G$ were carried out against a distribution generated from 100 iterations of simulated CGs using random $\mathrm{CV}$ values. $C G$ values were significant if they fell outside the $95 \%$ confidence intervals around the mean of the simulated CGs (Kitchell \& MacLeod 1988, Foote 1996). The inherent midpoint of the time interval, $C G_{1}$ (Foote 1996), was also calculated, using equal $\mathrm{CVs}$ in each time interval. Positive differences between $C G$ and $C G_{1}$ reflect a wider range in sizes towards the end of the season, and negative differences between $C G$ and $C G_{1}$ indicate that the size variation was greater at the beginning of the season.

The Gini coefficient $(G)$ can be used to describe the development of size inequalities in resource limited systems, where low values in $G$ indicate a uniform population (Poulin \& Latham 2002). The Gini coefficient was used to give a more detailed view of the development of size structure in each year. In our case $G$ describes the inequality of the fish sizes and was calculated according to Weiner \& Solbrig (1984), Creed et al. (1996) and Geffen (1996):

$$
G=\frac{\sum_{i=1}^{n} \sum_{i=1}^{n}\left|x_{i}-x_{j}\right|}{2 n^{2} \bar{x}}
$$

$x_{i}=$ length of the $i$ th individual, $x_{j}=$ length of the $j$ th individual, $\bar{x}=$ mean length of all individuals, $n=$ total number of individuals. Bootstrap estimates of the Gini coefficient were calculated using an SAS macro (SAS Institute, GINI macro by P. Johnson).

\section{RESULTS}

Mean length, weight and condition, and growth rates

Mean lengths of juvenile plaice on the Port Erin Bay nursery ground varied seasonally as expected and the patterns varied inter-annually. The mean lengths on specific dates were higher in 1997 and 1998 than in 1994-1996 (Fig. 2a). In both 1995 and 1997 mean weights changed very little after the end of July, whereas in 1996 and 1998 mean weights continued rising through the end of the summer period. Mean weights on specific dates were also higher in 1997 and 1998 (Fig. 2b). There were no clear patterns in the 

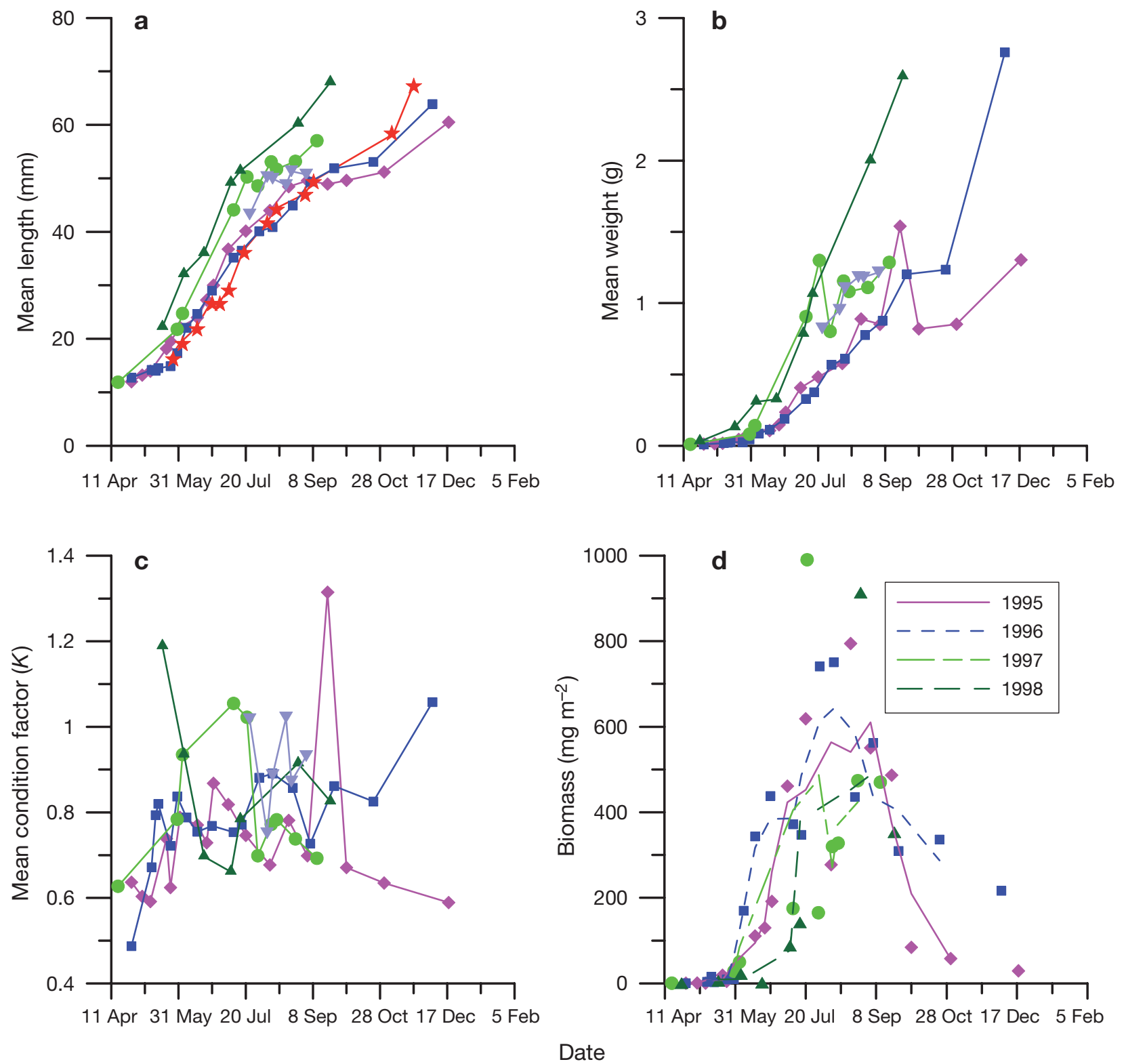

Fig. 2. Pleuronectes platessa. Seasonal changes of juvenile plaice in Port Erin Bay, Isle of Man. (a) Mean length, (b) mean weight, (c) mean condition and (d) density (biomass) with trend lines. $\star=1994, \diamond=1995, \square=1996, \bullet=1997, \Delta=1998, \nabla=1999$

average condition of fish for any of these years, despite the differences in growth rates (Fig. 2c).

Both temperature and population density can affect growth rates but it is difficult to disentangle the separate effects in a field study. Over all years at each site growth rate did not vary linearly with maximum population size or temperature (linear regression, $\mathrm{p}>0.05$, see Table 1); however, higher growth rates tended to occur in warmer years and were negatively correlated with population densities (Spearman rank coefficient: -0.90 for Port Erin Bay, -0.78 for Ardmucknish Bay). Combining maximum population size (MPS) and temperature $(T)$ into an average rank score and comparing this with the ranked growth rates showed that the lowest growth rate occurred in 1996 due to a combination of lower temperature and higher density (Table 1).

On the Ardmucknish Bay nursery ground the increases in mean length slowed from the beginning of September onward (Fig. 3). In 3 years (1989, 1995 and 1996) mean length was substantially lower in early September than in other years sampled. In general, the growth rates of the Ardmucknish Bay population (Table 2) were substantially higher than the Port Erin Bay plaice. The highest growth rate $\left(0.61 \mathrm{~mm} \mathrm{~d}^{-1}\right)$ occurred in the year when the estimated population density was at its lowest and the lowest growth rate 
Table 1. Pleuronectes platessa. Growth rate, instantaneous growth rate (IGR), maximum population size (MPS) and instantaneous mortality (standard mortality rate, SMR; see Nash \& Geffen 2000) of juvenile plaice and mean water temperature (1 May to 31 August) in Port Erin Bay, Isle of Man. Avg. rank scores determined by avg. water temperature and max. population size measured in Port Erin Bay. Ranking by growth rate (high to low), water temperature (high to low) and population density (low to high) (see Nash et al. 1994). Difference in ranks = average rank - growth rate rank. Mortality rates in bold from non-significant regressions

\begin{tabular}{|c|c|c|c|c|c|c|c|c|}
\hline Year & $\begin{array}{l}\text { Growth rate } \\
\mathrm{mm} \mathrm{d}^{-1} \text { (rank) }\end{array}$ & $\begin{array}{c}\operatorname{IGR}(g) \\
\left(\mathrm{g} \mathrm{d}^{-1}\right)\end{array}$ & $\begin{array}{l}\text { Temp. }(T) \\
\left({ }^{\circ} \mathrm{C}\right)\end{array}$ & MPS & $\begin{array}{l}\mathrm{SMR} \\
\left(\mathrm{d}^{-1}\right)\end{array}$ & $\begin{array}{c}\text { Avg. rank } \\
\text { (incl. } T \text { and MPS) }\end{array}$ & $\begin{array}{l}\text { Diff. in } \\
\text { rank order }\end{array}$ & $\begin{array}{c}-\mathrm{SMR} / g \\
(\mathrm{~g})\end{array}$ \\
\hline 1994 & $0.322(3)$ & & 11.69 & 121851 & 0.0238 & 4 & 1 & no data \\
\hline 1995 & $0.318(4)$ & 0.0148 & 12.58 & 128214 & 0.0290 & 3 & -1 & -1.959 \\
\hline 1996 & $0.297(5)$ & 0.0146 & 11.70 & 304354 & 0.0212 & 4.5 & -0.5 & -1.452 \\
\hline 1997 & 0.362 (1) & 0.0144 & 12.43 & 76205 & 0.0100 & 2.5 & 1.5 & -0.694 \\
\hline 1998 & $0.352(2)$ & 0.0122 & 12.91 & 34251 & 0.0160 & 1 & -1 & -1.311 \\
\hline
\end{tabular}

$\left(0.33 \mathrm{~mm} \mathrm{~d}^{-1}\right)$ when the estimated density was at its highest. This year (1986) was the only year to show clear self-thinning patterns (see next section). Mortality rates were generally higher in Port Erin Bay than in Ardmucknish Bay, especially in the years 1995 to 1997.

\section{Self-thinning}

At both sites the density and mean weight of individuals varied through each year (Fig. 4), generally in a pattern that was consistent with the dynamics illustrated in Fig. 1. The self-thinning rule predicts that there should be a maximum fish density for a given mean fish weight and that the relationship between log density and log mean weight, measured at different times over the season, should have a slope of between -1.3 and -1.5 depending on the underlying controlling factors. In only 1 yr in each data set (1996 in Port Erin Bay and 1986 in Ardmucknish Bay) (Fig. 4, Table 3) was there a signifi- cant relationship between the reduction in density with an increase in mean weight. In the case of Port Erin Bay the slope of the dynamic thinning line was substantially different from the expected $(-0.88)$, whereas in Ardmucknish Bay it was close to expected (-1.32). In both cases the start of this trajectory occurred in early June. In all other years the density to weight trajectories in both areas rarely reached these boundaries, and even when they did, the values did not cross the site specific dynamic thinning line.

The site specific dynamic thinning lines at each beach (relationship between log density and log mean weight) were significant (Table 3) with slopes of -1.17 $(-1.35$ to $-0.99+/-1 \mathrm{SD})$ and $-1.23(-1.49$ to -0.97 $\pm 1 \mathrm{SD})$ for Port Erin Bay and Ardmucknish Bay respectively. There were no significant differences in the slopes; however, there were significant differences in the elevations. In addition, in each case the slope tended to become steeper in the latter part of the year, usually starting around September (Figs. $1 \& 4$ ).
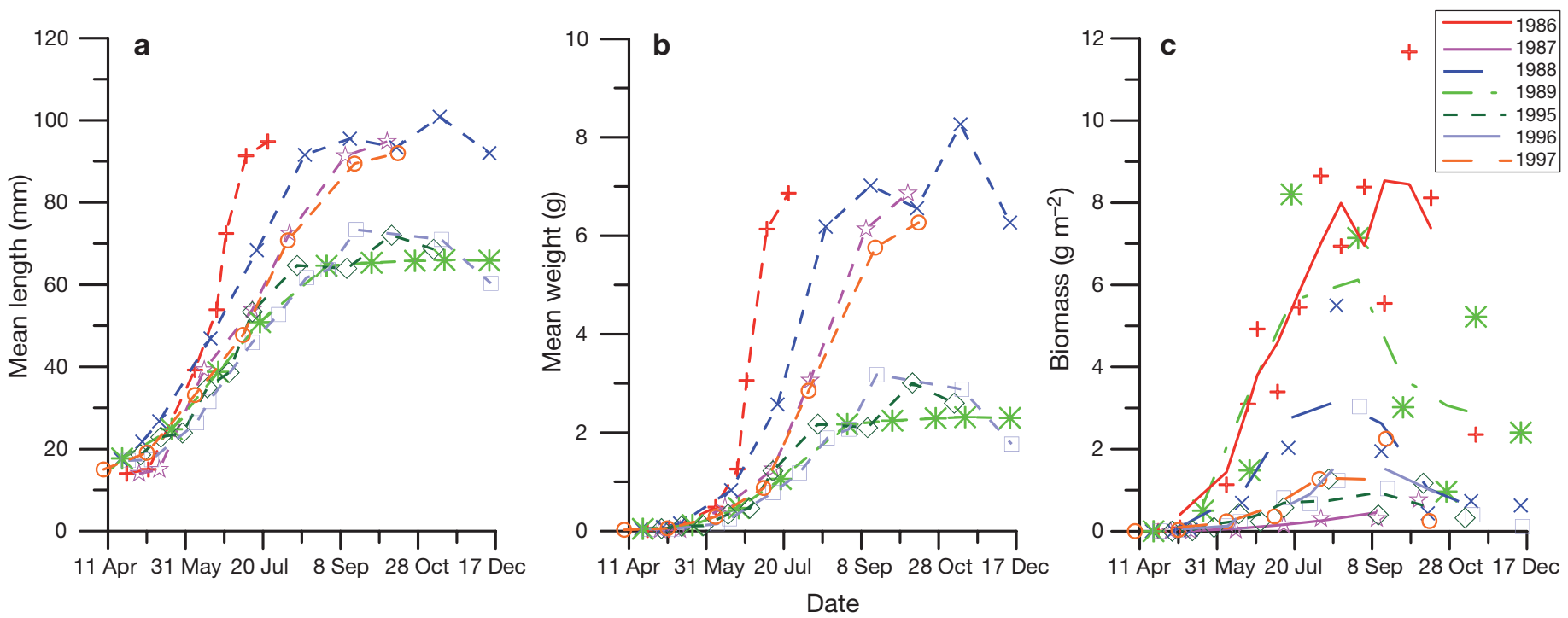

Fig. 3. Pleuronectes platessa. Seasonal changes in (a) mean length, (b) mean weight, (c) density (biomass) of juvenile plaice at Ardmucknish Bay, Oban, Scotland. $+=1986$, $*=1987, x=1988$, 我 $=1989, \diamond=1995, \square=1996, \bigcirc=1997$ 
Table 2. Pleuronectes platessa. Inter-annual variation in growth rate (May to September), instantaneous growth rate (IGR), maximum density and instantaneous mortality (standard mortality rate, SMR) of juvenile plaice in Ardmucknish Bay (Oban, Scotland) nursery ground. Rank order for growth rate (high to low) and maximum density (low to high) is also given. Bold: from nonsignificant regressions

\begin{tabular}{|c|c|c|c|c|c|c|c|c|}
\hline Year & $\begin{array}{l}\text { Growth rate } \\
\mathrm{mm} \mathrm{d}^{-1} \text { (rank) }\end{array}$ & $\begin{array}{c}\operatorname{IGR}(g) \\
\left(g^{-1}\right)\end{array}$ & $\underset{\left({ }^{\circ} \mathrm{C}\right)}{\text { Temp. }}(T)$ & $\begin{array}{l}\text { Max. density } \\
\mathrm{m}^{-2} \text { (rank) }\end{array}$ & $\begin{array}{l}\text { SMR } \\
\left(d^{-1}\right)\end{array}$ & $\begin{array}{c}\text { Avg. rank } \\
\text { (incl. } T \text { and max. den.) }\end{array}$ & $\begin{array}{l}\text { Diff. in } \\
\text { rank order }\end{array}$ & $\underset{(\mathrm{g})}{-\mathrm{SMR} / \mathrm{g}}$ \\
\hline 1986 & $0.331(7)$ & 0.0131 & $10.67(6)$ & $14.39(7)$ & 0.0088 & 6.5 & -0.5 & -0.672 \\
\hline 1987 & 0.607 (1) & 0.0196 & $10.67(6)$ & $0.12(1)$ & 0.0036 & 3.5 & 2.5 & -0.184 \\
\hline 1988 & $0.596(2)$ & 0.0159 & $11.92(4)$ & 7.02 (5) & 0.0159 & 4.5 & 2.5 & -1.000 \\
\hline 1989 & $0.398(6)$ & 0.0110 & $12.60(1)$ & $7.74(6)$ & 0.0101 & 3.5 & -2.5 & -0.918 \\
\hline 1995 & $0.478(4)$ & 0.0134 & $12.03(3)$ & $1.25(3)$ & 0.0115 & 3 & -1 & -0.858 \\
\hline 1996 & 0.436 (5) & 0.0140 & $11.85(5)$ & $1.46(4)$ & 0.0154 & 4.5 & -0.5 & -1.100 \\
\hline 1997 & $0.542(3)$ & 0.0153 & $12.13(2)$ & $0.83(2)$ & 0.0180 & 2 & -1 & -1.177 \\
\hline
\end{tabular}

Table 3. Pleuronectes platessa. Dynamic thinning lines for Port Erin Bay and Ardmucknish Bay. Both the annual dynamic thinning lines and the site specific thinning lines are given where there was a significant relationship between log density and log mean weight; ns = not significant

\begin{tabular}{|c|c|c|c|c|c|c|c|}
\hline \multirow{2}{*}{$\frac{\text { Location }}{\text { Port Erin Bay }}$} & \multirow{2}{*}{$\begin{array}{l}\text { Year } \\
1995\end{array}$} & \multicolumn{2}{|c|}{ Date range } & \multirow{2}{*}{$\frac{\mathrm{N}}{9}$} & \multirow{2}{*}{$\frac{\text { Slope (SE) }}{\mathrm{ns}}$} & \multirow[t]{2}{*}{ Intercept (SE) } & \multirow{2}{*}{$\frac{p}{>0.05}$} \\
\hline & & 14 Jun & $19 \mathrm{Sep}$ & & & & \\
\hline & 1996 & 13 Jun & $22 \mathrm{Oct}$ & 10 & $-0.885(0.135)$ & $-0.350(0.046)$ & $<0.001$ \\
\hline & 1997 & $21 \mathrm{Jul}$ & $11 \mathrm{Sep}$ & 6 & $\mathrm{~ns}$ & & $>0.05$ \\
\hline & 1998 & $09 \mathrm{Jul}$ & 21 Sep & 4 & ns & & $>0.05$ \\
\hline & 1999 & $23 \mathrm{Jul}$ & 23Aug & 5 & ns & & $>0.05$ \\
\hline \multirow{7}{*}{ Ardmucknish Bay } & 1986 & 20 Jun & 02 Oct & 8 & $-1.318(0.375)$ & $1.097(0.345)$ & $=0.013$ \\
\hline & 1987 & $13 \mathrm{Jul}$ & 08 Oct & 4 & ns & & $>0.05$ \\
\hline & 1988 & 15 Jun & 13 Oct & 5 & ns & & $>0.05$ \\
\hline & 1989 & $18 \mathrm{Jul}$ & $14 \mathrm{Nov}$ & 5 & $\mathrm{~ns}$ & & $>0.05$ \\
\hline & 1995 & 14 Jun & 11 Oct & 6 & $\mathrm{~ns}$ & & $>0.05$ \\
\hline & 1996 & $12 \mathrm{Jul}$ & $17 \mathrm{Sep}$ & 5 & ns & & $>0.05$ \\
\hline & 1997 & 06 Jun & 15 Oct & 5 & ns & & $>0.05$ \\
\hline \multicolumn{8}{|l|}{ Site specific } \\
\hline Port Erin Bay & & 13 Jun & $11 \mathrm{Sep}$ & 11 & $-1.17(0.18)$ & $-0.23(0.05)$ & 0.0001 \\
\hline Ardmucknish Bay & & 26 Jun & 2 Oct & 10 & $-1.23(0.26)$ & $1.02(0.23)$ & 0.0015 \\
\hline
\end{tabular}
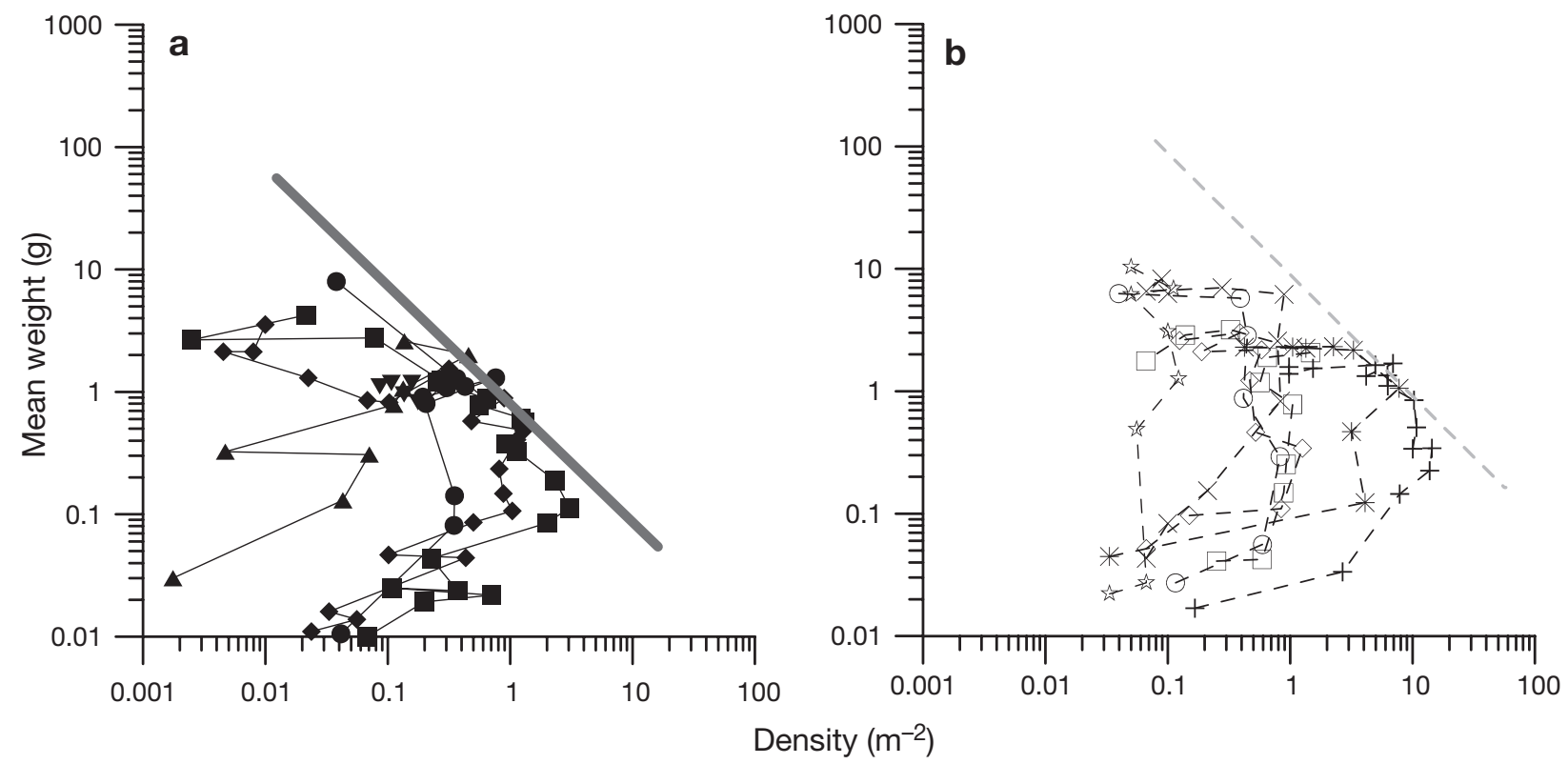

Fig. 4. Pleuronectes platessa. Relationship between density and mean weight of juvenile plaice on 2 small nursery grounds in (a) Port Erin Bay, Isle of Man, Irish Sea and (b) Ardmucknish Bay, Lynn of Lorne, Scotland on the west side of the British Isles. Symbols as in Figs. $2 \& 3$ 


\section{Population size structure}

In general, the Gini coefficient $G$ (a measure of the equality in the size distribution on each sampling date over the year) was relatively low (0.04 to 0.2$)$ reflecting the tendency for sizes to be relatively uniform on nursery grounds. The Gini coefficient is not a measure of the variation in size between the smallest and the largest individuals, but rather a measure of how evenly the individuals are distributed across the entire length range. The seasonal pattern in $G$ on both nursery grounds showed an increasing inequality (heterogeneous size structure) from settlement through to early

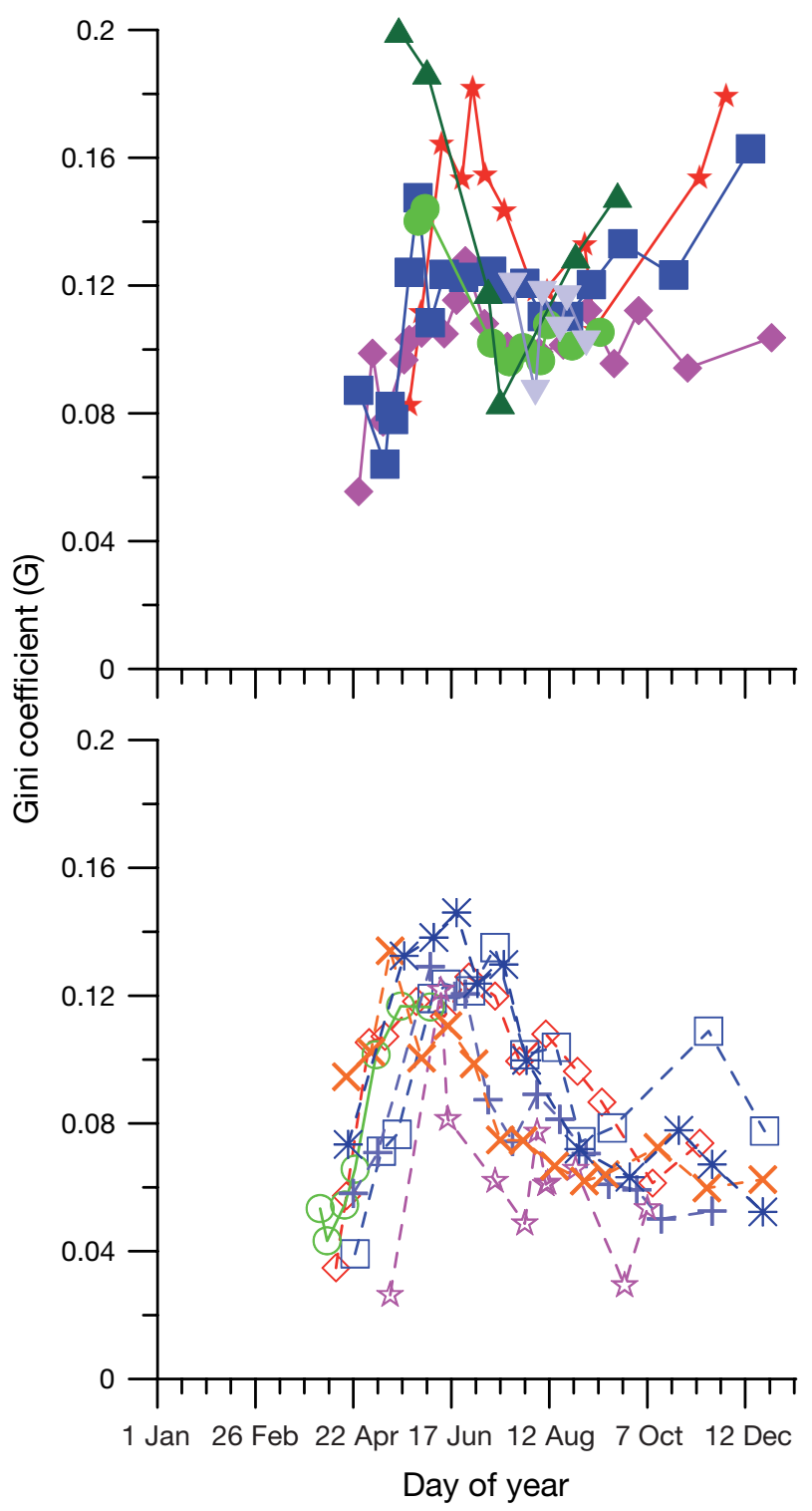

Fig. 5. Pleuronectes platessa. Seasonal variation in the Gini coefficient for juvenile plaice lengths in (a) Port Erin Bay, Isle of Man, Irish Sea and (b) Ardmucknish Bay, Scotland. Symbols as in Figs. $2 \& 3$
June (Fig. 5). The seasonal changes in $G$ differed between years. For example, in Port Erin Bay, $G$ increased in early May in 1998, and declined rapidly thereafter. In contrast, the peak in size inequality occurred in late June in 1994. In most years there was relatively little alteration in the size structure between June and early September for Port Erin Bay and slightly later (early July to early November) in Ardmucknish Bay. Size inequality increased after September in 1994, 1996 and 1998 in Port Erin Bay, even though the populations at this time were very much reduced in abundance, mainly due to emigration off the nursery grounds.

A similar pattern was seen in the relationship between $G$ and the mean length of individuals in the population (Fig. 6 for Port Erin Bay). This was not surprising since length tended to increase with time due to growth. The increase in inequality occurred through the settlement period as new small individuals arrived whilst the larger individuals continued growing. At the end of settlement the influence of new arrivals ceased. In 1995 and 1996 there appeared to be little change in the size structure as mean length increased. In other years inequalities in size structure decreased as mean length increased. Whether this is due to differences in individual growth rate, selective mortality or emigration is uncertain. There was no apparent relationship between $G$ and population density (Fig. 7).

The centre of gravity, which expresses the timing of the mean diversity in size, was calculated based on the

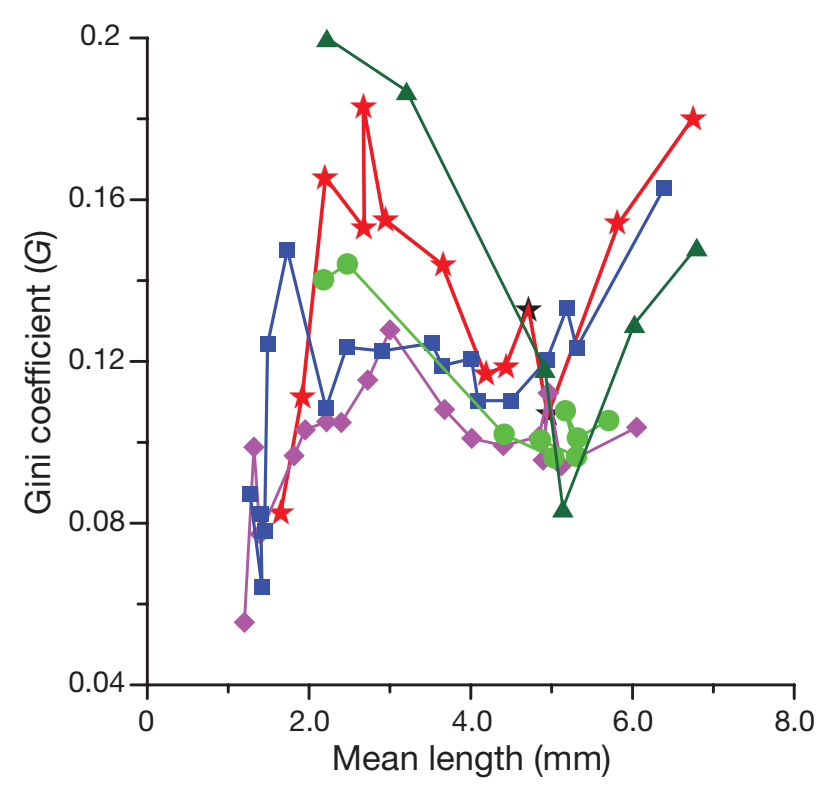

Fig. 6. Pleuronectes platessa. Variation in the Gini coefficient with changes in mean length of juvenile plaice on the Port Erin Bay nursery ground. Symbols as in Fig. 2 


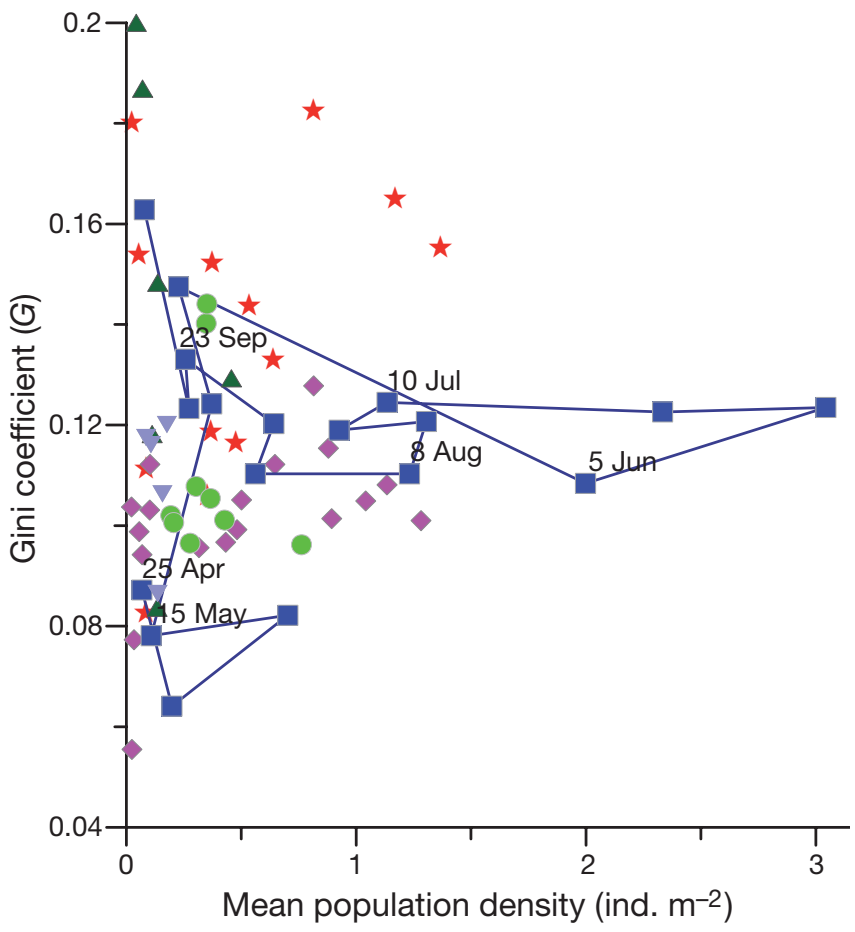

Fig. 7. Pleuronectes platessa. Relationship between density of plaice on the nursery ground and the Gini Coefficient. Annual trajectory for 1996 is given for illustrative purposes. Symbols as in Fig 2

$\mathrm{CV}$ in length of each sample date. $C G$ varied between years (Table 4), and values were significantly different from random in all cases except for Ardmucknish Bay in 1988. In Port Erin Bay, $C G$ and thus heterogeneity occurred significantly later than the midpoint of the season in all years. $C G$ was latest in the season in 1994 and earliest in 1997. In Ardmucknish Bay, CG occurred significantly earlier than the midpoint in 1986, 1987, and 1989, but significantly later than the midpoint in 1995, 1996 and 1997. In Ardmucknish Bay, CG occurred earlier in years with a high growth rate and low population size.

The centre of gravity can be affected by mortality rates on the nursery grounds. In Ardmucknish Bay there was a tendency for earlier CGs to occur with lower mortality rates (Fig. 8). However, this relationship was not apparent in Port Erin Bay. In Port Erin Bay the mortality rates did not appear to be directly related to the maximum population size (Fig. 9). There appeared to be 2 distinct relationships between maximum population size and the mortality rates: low population size and mortality (1997 \& 1998), and higher population sizes associated with a higher mortality (1994 to 1996). These much higher mortality rates in Port Erin Bay did not shift $C G$ to a much earlier date as suggested by the data for Ardmucknish Bay (see Fig. 8).

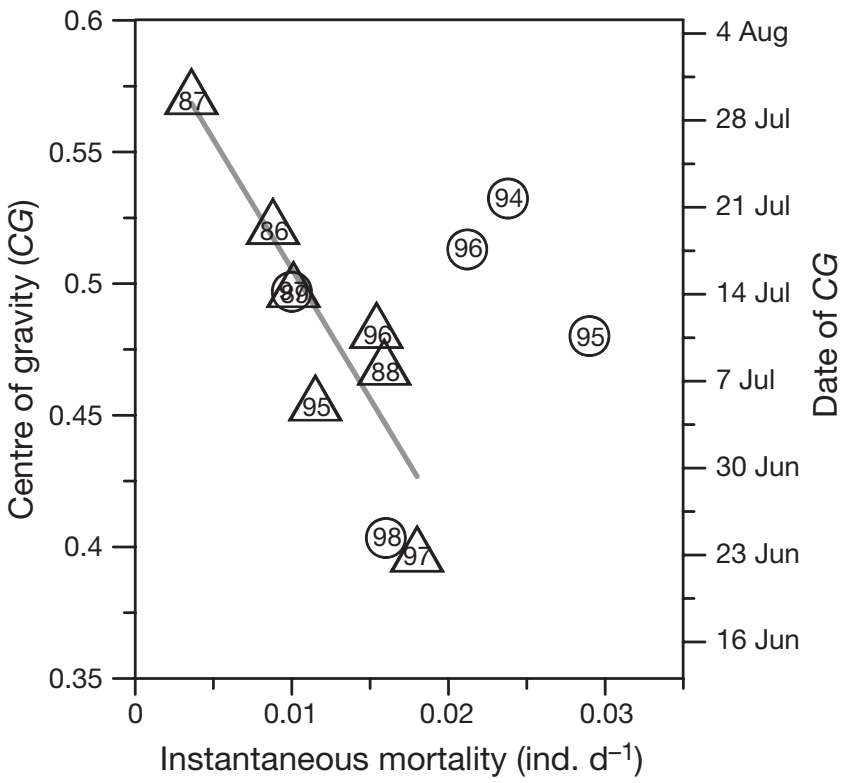

Fig. 8. Pleuronectes platessa. Relationship between the instantaneous mortality rate of juvenile plaice on nursery ground between July and October each year and the timing of maximum size heterogeneity as represented by the centre of gravity of the length distributions. $\mathrm{O}=$ Port Erin Bay, $\Delta=$ ' $86-$ ' 88 and '95-'97 and $-=$ Ardmucknish Bay

\section{Biomass and maximum consumption rates}

Similar patterns in the seasonal variation in biomass were seen in both Port Erin Bay and Ardmucknish Bay (Figs. 2d \& 3c). In both bays there were inter-annual differences, however, and these differences were very

Table 4. Pleuronectes platessa. Summary of estimates of centre of gravity $(C G)$ for Port Erin and Ardmucknish Bays. $\mathrm{N}=$ number of sampling dates within the time period 1 April to 1 November used to estimate $C G, C G_{1}=$ inherent midpoint of the time interval used to estimate $C G$. Test of significance based on 100 iterations with random values of CV to give a simulated CG (mean: 0.4685; variance: 0.0027). Bold: not significantly different from random

\begin{tabular}{|lccccc|}
\hline Location & Year & $\mathrm{N}$ & $C G$ & $C G_{1}$ & $\begin{array}{c}C G \text { relative } \\
\text { to mean date }\end{array}$ \\
\hline Port Erin Bay & 1994 & 13 & 0.5323 & 0.5269 & 0.005 \\
& 1995 & 18 & 0.4801 & 0.4692 & 0.011 \\
& 1996 & 19 & 0.5130 & 0.4751 & 0.038 \\
& 1997 & 12 & 0.4969 & 0.4860 & 0.011 \\
& 1998 & 10 & 0.4034 & 0.3842 & 0.019 \\
Ardmucknish & 1986 & 15 & 0.5238 & 0.5634 & -0.040 \\
Bay & 1987 & 17 & 0.5732 & 0.5914 & -0.018 \\
& 1988 & 15 & $\mathbf{0 . 4 7 0 4}$ & 0.5284 & \\
& 1989 & 12 & 0.4999 & 0.5497 & -0.050 \\
& 1995 & 15 & 0.4568 & 0.4243 & 0.032 \\
& 1996 & 11 & 0.4843 & 0.4308 & 0.054 \\
& 1997 & 9 & 0.3994 & 0.3528 & 0.047 \\
\hline
\end{tabular}


pronounced in Ardmucknish Bay. In both bays maximum biomass occurred in late July to early September. The major difference between the 2 bays was the large difference in maximum biomass (Port Erin Bay: $1 \mathrm{~g}$ $\mathrm{m}^{-2}$; Ardmucknish Bay: $12 \mathrm{~g} \mathrm{~m}^{-2}$ ).

The maximum consumption rates of the population were only estimated for Port Erin Bay and expressed as mg AFDW $\mathrm{m}^{-2}$ and $\mathrm{g}$ wet $\mathrm{wt} \mathrm{m}^{-2}$. Both measures showed that maximum consumption occurred in late July to early September (Fig. 10). Values of consumption in wet weight were highest in 1995, while AFDW values for consumption were highest in 1996. Over the 4 years examined here, maximum wet weight consumption by the juvenile plaice population was ca. $4 \mathrm{~g}$ $\mathrm{m}^{-2}$ and ca. $25 \mathrm{mg}$ AFDW $\mathrm{m}^{-2}$. The maximum consumption rates for the population declined from early September to the end of the year even though the mean lengths of individuals continued to increase (see Fig. 3a). Mean weight generally remained high or increased but there was a substantial decrease in fish abundance.

\section{DISCUSSION}

Armstrong (1997) comprehensively evaluated the application of self-thinning theory to salmonid populations. He concluded that the development of juvenile salmonid populations seemed to exhibit self-thinning, but cautioned that the slope of the mean size:density

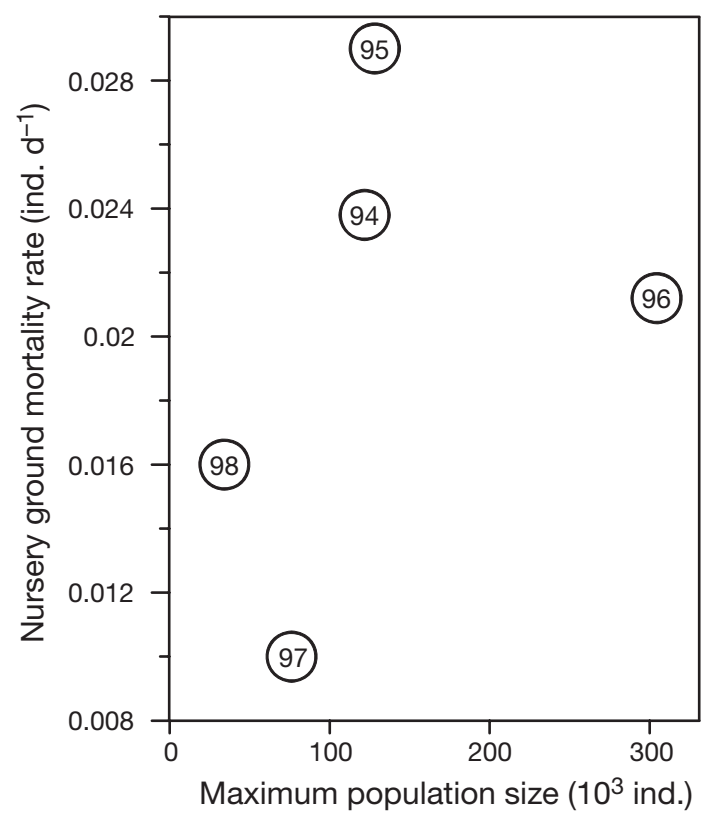

Fig. 9. Pleuronectes platessa. Relationship between instantaneous mortality rate of juvenile plaice between July and October each year from 1994 to 1997 and annual maximum population size in Port Erin Bay
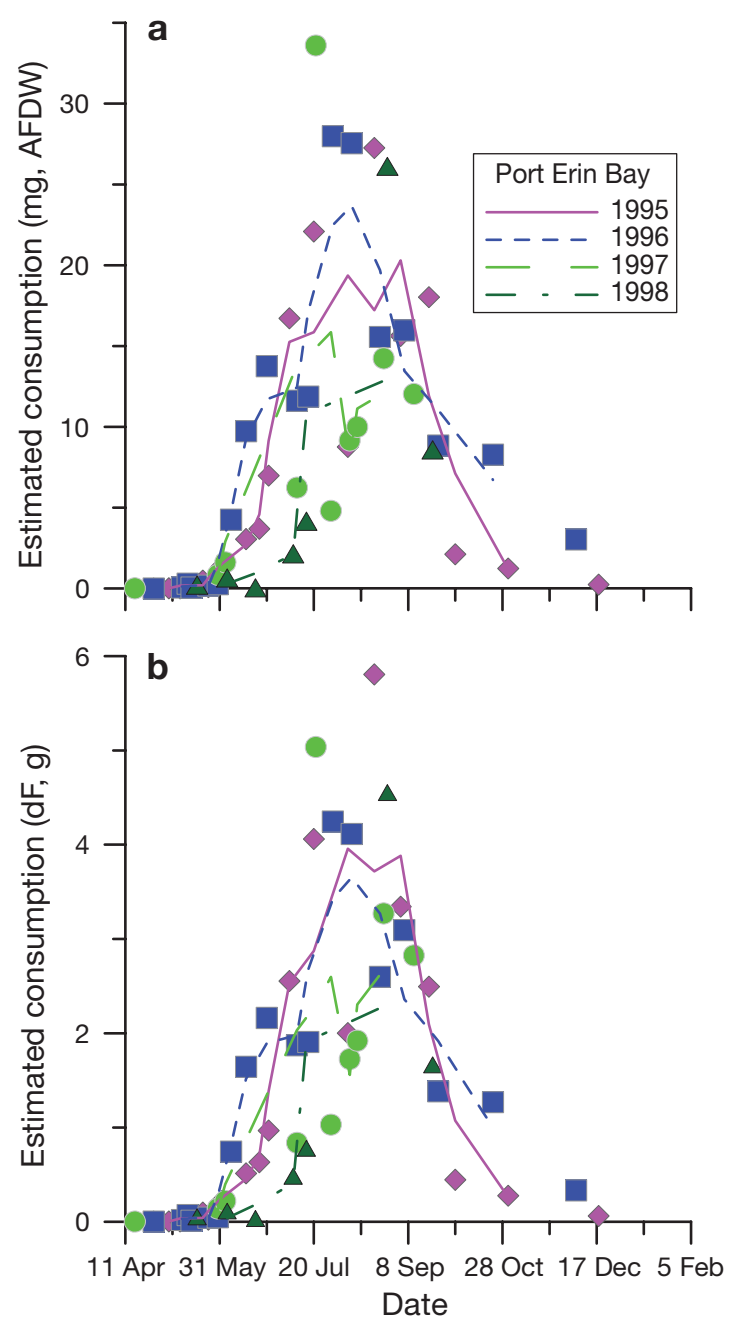

Fig. 10. Pleuronectes platessa. Seasonal variation in maximum consumption rate of the plaice population in Port Erin Bay. Lines are 3 point running averages: (a) estimated consumption in $\mathrm{mg}$ AFDW $\mathrm{m}^{-2}$ and (b) estimated consumption in $\mathrm{g}$ wet wt $\mathrm{m}^{-2}$. Symbols as in Fig. 2

relationship would be equal to $-1.33(-4 / 3)$ only during the first summer of life. Later stages would exhibit relationships with steeper or shallower slopes, depending on the temporal stability of the food supply and other factors such as the consumption to body weight scaling. Armstrong (2005) further developed the self-thinning model to evaluate habitat quality for Atlantic salmon.

Although utilised in numerous studies of salmonid populations (e.g. Elliott 1993, Grant 1993, Bohlin et al. 1994, Armstrong 1997, Dunham et al. 2000, Keeley 2003), the concept of self-thinning has not been applied to marine fish populations. Juvenile flatfish nursery grounds provide an ideal test bed for the concepts of self-thinning in animals and carrying capacities. The areas have a seasonal flux of abundance; populations start with very small individuals, which undergo rapid 
growth in size, and then numbers decline over the next 6 mo. This reduction in numbers prior to settlement of the new year class ensures limited intra-specific, intercohort competition and/or predation.

\section{Population size structure}

The juvenile plaice population at Port Erin Bay in 1996 and Ardmucknish Bay in 1986 developed following dynamic thinning lines. In other years the population sizes were not high enough to invoke selfthinning. These observations may explain the variable evidence for density dependent effects on flatfish nursery grounds. Self-thinning or dynamic thinning lines clearly describe population changes in the context of resource limitation and intra-specific competition (Armstrong 1997, Begon et al. 2006). Thus, such patterns will only be evident on nursery grounds at very high population levels. In these situations it appears that the nursery ground populations are similar to other animal populations and there are identifiable dynamic thinning models.

Population size structure can be a sensitive indicator of changes and mechanisms which are not revealed at the level of density, abundance or mean size (Geffen 1996). The analysis of size hierarchies and changes in size distributions in fish populations is more often considered in aquaculture applications (Imsland et al. 1998) than in natural marine fish populations. In plant populations, increases in density should be accompanied by increases in Gini coefficient $G$ if interference results in dominance and suppression (Weiner \& Solbrig 1984). If dominance by large individuals (elevated $G_{i}$ Santos 1995) or size-selective survival (leading to similar sized individuals, self-thinning, reduced Gini coefficient; Creed et al. 1996, Dunham et al. 2000) occurs, a change in Gini coefficient should be visible at least in the 1996 Port Erin data. In fact, during the period after maximum abundance in 1996 the Gini coefficient remained reasonably stable, suggesting that the relative size structure within the population remained stable, i.e. further reductions are not size selective. This does not, however, rule out the possibility of adjustments in individual growth rates to maintain the size structure. The largest changes in the size structure of the population occur early in the season (during the settlement period) and later in the season (during the period of emigration). In general, the CVs of juvenile plaice lengths tend to increase early in the year and then to decline as the population ages and grows (van der Veer et al. 1994).

$C G$ indicates that the timing of maximum heterogeneity in the population varied between years, occurring between the end of June and the end of July. In
Ardmucknish Bay the lowest mortality rates were associated with a later $C G$. Thus, reductions in size variability were manifested later in the year when mortality was higher, and this could be indicative of size selective mortality reducing size variability earlier in the season. In Port Erin Bay the much higher mortality rates did not translate into a much earlier $C G_{\text {; }}$ alternatively, the much lower mortality rates in the 2 years (1997 and 1998) did not result in CGs being much later in the year. There is obviously a necessity to examine the mechanisms influencing the size structure of these populations, and these data suggest that there may be more than one mechanism.

\section{Self-thinning and flatfish nursery grounds}

There has been much research undertaken on flatfish nursery grounds, yet the mechanisms operating and processes governing survival are still poorly known. Recent work on one small nursery ground in the Irish Sea (Nash \& Geffen 2000) suggests that the year class strength of an annual cohort can be determined on the nursery grounds rather than in the pelagic phase. It is therefore important to examine the nursery ground phase more critically. Habitat quality of a nursery ground can affect growth rates and survival (Gibson 1994). Probably the most important factors for these non-territorial fish are food availability, predation and temperature. The production and densities of juvenile plaice on nursery grounds varies considerably. In general, growth rates are related to a combination of temperature and food quantity and quality (van der Veer \& Witte 1993). High population densities reduce growth through density dependent effects, and resource limitation and low temperatures reduce growth rates through physiological processes. The differences in growth rate of the juvenile plaice between Port Erin Bay and Ardmucknish Bay are probably primarily due to prey quality and/or quantity since the thermal regimes do not differ by much, especially in the years where both were sampled at the same time (1995 to 1997). An alternative hypothesis could be size selective predation, whereby the smaller individuals are removed more frequently on the Ardmucknish Bay nursery ground, resulting in an apparently higher growth rate, or a positive size selective predation (removal of the larger plaice) on the Port Erin Bay nursery ground, resulting in an apparent lower growth rate (see van der Veer et al. 2000).

The quantity of food on these nursery grounds increases with time as the benthic prey populations develop over the season, resulting in an increase in the growth rate of the plaice (sensu Begon et al. 1986). During this time period the water temperature is 
increasing in line with the change in thermal regime (see Nash et al. 1994), also resulting in an increase in the growth rate of the plaice. These changes in the food and temperature regime should alter the slope of the self-thinning line (Armstrong 1997). As predicted, in both populations of juvenile plaice the slope of the density-size relationship often became shallower $(>-4 / 3)$ toward the end of the summer season. The shallower slope is also consistent with the consumption of the population outstripping the growth of the food (Begon et al. 1986). Bohlin et al. (1994) also point out that if food production is not even for all size classes of fish, then the self-thinning line may be concave rather than straight. The concave trajectories of the 'lines' in both bays may reflect intra-annual changes in food combined with a change in size structure of the population.

Migrations and other changes in behaviour also alter the slope of the dynamic thinning line (Begon et al. 1986). Juvenile plaice emigrate off the nursery grounds into deeper water in late summer and autumn (Gibson et al. 2002). Emigration of these larger individuals could be a response to food limitation or the result of release of predation pressure as they grow out of a predation window and can safely move into deeper water. Both mechanisms would alter the slope of the dynamic thinning line. Such changes in slope may be characteristic of different life history stages (Armstrong 1997).

It is debatable whether there is food limitation on plaice nursery grounds (van der Veer \& Witte 1993), although it may be inferred from sub-optimal growth rates late in the season (Nash et al. 1994). Food limitation is more often postulated for newly settled individuals at the beginning of season (Amara \& Paul 2003), but the evidence is almost entirely based on growth rate analyses, and the discussion of carrying capacity on flatfish nursery grounds is not conclusive. Lockwood (1984) ascribed observed reductions in growth rate to shortening day lengths rather than reduced prey abundance. Individually tagged plaice grew at reduced rates during autumn (Nash et al. 1994), and most probably foraged over a larger area in response to declining in prey availability. The question of 'starvation' or food limitation on juvenile flatfish nursery grounds has been debated for many years. Steele \& Edwards (1970) suggest that food limitation does occur in juvenile plaice populations. In contrast, working with the maximum growth/optimal food condition hypothesis, van der Veer \& Witte (1993) suggested that food is generally not limiting. The interannual variation in population size at Port Erin and Ardmucknish Bays suggested that food can become limiting in some years, depending on the numbers of individuals that settle relative to the productivity of the nursery ground. In general, the evaluation of ecologi- cal concepts for flatfish nursery grounds suffers from a lack of information on food availability and size distributions of the fish populations and the changes in these parameters over time.

In 2 experimental studies food limitation was identified as the principal cause of emigration which then resulted in reduced population densities (Dunham et al. 2000). In Dunham et al. (2000) the fish that emigrated or died had a biomass similar to starving fish, which suggested that fish did not emigrate until close to starvation death. In general, the condition of juvenile flatfish on the nursery grounds is high, and it is rare to find individuals with very low condition factors. Although starvation is difficult to document in the field, it does not rule out the possibility that a lack of food does affect the energetic reserves of individuals and therefore make them more susceptible to other sources of mortality.

Juvenile plaice from Port Erin Bay may emigrate into deeper water at an earlier date than those from Ardmucknish Bay. Bohlin et al. (1994) suggested that where the mortality $(m)$ versus growth $(g)$ relationship $(-m / g)$ was steeper (e.g. 1994 and 1998 in Port Erin Bay and 1996 and 1997 in Ardmucknish Bay; see Tables 1 and 2), there would be greater pressure for emigration off the nursery ground. The resulting reduction in mean size at Port Erin compounds the differences in production between the bays. Bohlin et al. (1994) suggested that ontogenetic habitat shifts which minimise $\mathrm{m} / \mathrm{g}$ are more likely to occur for segments of a population that are not regulated by density-dependent growth and/or mortality. In the Port Erin and Ardmucknish plaice populations the only evidence for density-dependence was in reduced growth rate at the highest densities observed. However, fluctuations in the thermal regime could also mask density-dependent effects. In addition, low spawning stock sizes may produce fewer settling plaice, such that the numbers of juveniles on the nursery grounds very rarely reach the carrying capacity and thus rarely invoke any density regulating effects. Keeley (2003) pointed out that in salmonid stream populations the density has to be above a minimum level of habitat saturation for selfthinning to become apparent.

The differences in the elevations of the 2 site-specific dynamic thinning slopes for the 2 nursery areas reflect the differences in productivity of these areas. The higher elevation means that the carrying-capacity of Ardmucknish Bay is higher than Port Erin Bay. The real differences between the 2 sites are probably greater because the densities for Armucknish Bay were not corrected for gear efficiency. The differences and similarities between the sites is an expected result and gives an indication of the similarities in processes operating on these flatfish nursery grounds and the 
variability in densities of fish that can be supported. These results also demonstrate the potential for problems if large cohorts settle on a nursery ground or an enhancement (restocking) programme is put in place. The problem of stocking densities has been well studied in aquaculture with the recognition of 'selfthinning' and estimating optimal stocking densities (e.g. Armstrong 2005, Fréchette et al. 2005). Similar analytical techniques and predictive relationships could be used for the estimation of yields from natural populations.

One final point to be considered is the effect of species interactions (Blackburn \& Gaston 2001). Assemblage-level interactions will affect the carrying capacity and trajectories of individual species that may appear as random noise in the present data series.

In conclusion, there are inter-site and intra-site differences in the development of the juvenile plaice populations on nursery grounds over the season. The intersite differences are seen as differences in the elevation of the self-thinning lines, with higher carrying capacity nursery grounds having more elevated bounds, i.e. a higher mean weight per unit density (see Fig. 1). We suspect that each of the nurseries has a characteristic slope elevation; however, whether this changes with a phase shift in environmental conditions is yet to be examined.

Acknowledgements. The authors are grateful to all those who helped with sampling flatfish nursery grounds over the years; on the Isle of Man: G. Hughes, T. Ellis, K. Dau and C. Corkill, and in Oban: L. Robb, S. Hill and G. Duncan. Sampling in 1995 to 1997 was supported by grant GST/02/902 from the UK Natural Environment Research Council as part of the 'Testable Models in Aquatic Ecosystems' Special Topic. We are also grateful to 3 anonymous reviewers for their helpful comments.

\section{LITERATURE CITED}

Amara R, Paul C (2003) Seasonal patterns in the fish and epibenthic crustaceans community of an intertidal zone with particular reference to the population dynamics of plaice and brown shrimp. Estuar Coast Shelf Sci 56: 807-818

Armstrong JD (1997) Self-thinning in juvenile sea trout and other salmonid fishes revisited. J Anim Ecol 66:519-526

Armstrong JD (2005) Spatial variation in population dynamics of juvenile Atlantic salmon: implications for conservation and management. J Fish Biol 67 (Suppl B):35-52

Begon M, Firbank L, Wall R (1986) Is there a self-thinning rule for animals? Oikos 46:122-24

Begon M, Townsend CR, Harper JL (2006) Ecology: from individuals to ecosystems. 4th edn. Blackwell Publishing, Oxford

Beverton RJH, Iles TC (1992) Mortality rates of O-group plaice (Pleuronectes platessa L.), dab (Limanda limanda L.) and turbot (Scophthalmus maximus L.) in European waters. II. Comparison of mortality rates and construction of life table for O-group plaice. Neth J Sea Res 29:49-59
Blackburn TM, Gaston KJ (2001) Linking patterns in macroecology. J Anim Ecol 70:338-352

Bohlin T, Dellefors C, Faremo U, Johlander A (1994) The energetic equivalence hypothesis and the relation between population density and body size in stream-living salmonids. Am Nat 143:478-493

Burrows MT, Gibson RN, Robb L, MacLean A (2004) Alongshore dispersal and site fidelity of juvenile plaice from tagging and transplants. J Fish Biol 65:620-634

Creed JC, Norton TA, Kain (Jones) JM (1996) Are neighbours harmful or helpful in Fucus vesiculosus populations? Mar Ecol Prog Ser 133:191-201

Dunham JB, Dickerson BR, Beever E, Duncan RD, Vinyard GL (2000) Effects of food limitation and emigration on selfthinning in experimental minnow cohorts. J Anim Ecol 69:927-934

Edwards RRC, Steele JH (1968) The ecology of O-group plaice and common dabs in Loch Ewe. I. Population and food. J Exp Mar Biol Ecol 2:215-238

Elliott JM (1986) Spatial distribution and behavioural movements of migratory trout Salmo trutta in a Lake District stream. J Anim Ecol 55:907-922

Elliott JM (1993) The self-thinning rule applied to juvenile sea trout, Salmo trutta. J Anim Ecol 62:371-379

Fonds M, Cronie R, Vethaak AD, Puyl P van der (1992) Metabolism, food consumption and growth of plaice (Pleuronectes platessa) and flounder (Platichthys flesus) in relation to fish size and temperature. Neth J Sea Res 29:127-143

Foote M (1991) Morphologocal and taxonomic diversity in a clade's history: the blastoid record and stochastic simulations. Contrib Mus Paleontol Univ Mich 28:101-140

Foote M (1996) Perspective: evolutionary patterns in the fossil record. Evolution 50:1-11

Fréchette M, Lefaivre D (1995) On self-thinning in animals. Oikos 73:425-428

Fréchette M, Alunno-Bruscia M, Dumais JF, Sirios R, Daigle G (2005) Incompleteness and statistical uncertainty in competition/stocking experiments. Aquaculture 246:209-225

Geffen AJ (1996) Effect of experimental manipulation of feeding conditions on the population structure of larval cod (Gadus morhua) and herring (Clupea harengus). Mar Freshw Res 47:291-300

Gibson RN (1994) Impact of habitat quality and quantity on the recruitment of juvenile flatfishes. Neth J Sea Res 32: 191-206

Gibson RN, Ansell AD, Robb L (1993) Seasonal and annual variations in abundance and species composition of fish and macrocrustacean communities on a Scottish sandy beach. Mar Ecol Prog Ser 98:89-105

Gibson RN, Robb L, Wennhage H, Burrows MT (2002) Ontogenetic changes in depth distribution of juvenile flatfishes in relation to predation risk and temperature on a shallowwater nursery ground. Mar Ecol Prog Ser 229:233-244

Goss-Custard JD, Stillman RA, West AD, Caldow RWG, McGrorty S (2002) Carrying capacity in overwintering migratory birds. Biol Conserv 105:27-41

Gould SJ (1988) Trends as changes in variance: a new slant on progress and directionality in evolution. J Paleo 62: 319-329

Gould SJ, Gilinski NL, German RZ (1987) Asymmetry of lineages and the direction of evolutionary time. Science 236:1437-1441

Grant JWA (1993) Self-thinning in stream-swelling salmonids. Can Spec Publ Fish Aquat Sci 118:99-102

Hughes RN, Griffiths CL (1988) Self-thinning in barnacles and mussels: the geometry of packing. Am Nat 132:484-491 
Hyder K, Nash RDM (1998) Variations in settlement pattern of Irish Sea plaice (Pleuronectes platessa L.) as determined from a simulation model. J Sea Res 40:59-71

Imsland AK, Nilsen T, Folkvord A (1998) Stochastic simulation of size-variation in turbot: possible causes analysed with an individual-based model. J Fish Biol 53:237-258

Kashiwai M (1995) History of carrying capacity concept as an index of ecosystem productivity (Review). Bull Hokkaido Nat Fish Res Inst 59:81-100

Keeley ER (2003) An experimental analysis of self-thinning in juvenile steelhead trout. Oikos 102:543-550

Kitchell JA, Macleod N (1988) Macroevolutionary interpretations of symmetry and synchroneity in the fossil record. Science 240:1190-1193

Latto J (1994) Evidence for a self-thinning rule in animals. Oikos 69:531-534

Lockwood SJ (1984) The daily food intake of O-group plaice (Pleuronectes platessa L.) under natural conditions: changes with size and season. J Cons Int Explor Mer 41: 181-193

Nash RDM, Geffen AJ (2000) The influence of nursery ground processes in the determination of year class strength in juvenile plaice Pleuronectes platessa L. in Port Erin Bay, Irish Sea. J Sea Res 44:101-110

Nash RDM, Geffen AJ, Hughes G (1994) Individual growth of juvenile plaice on an Irish Sea nursery ground (Port Erin Bay, Isle of Man). Neth J Sea Res 32:369-378

Poulin R, Latham ADM (2002) Inequalities in size and inten-

Editorial responsibility: Otto Kinne (Editor-in-Chief), Oldendorf/Luhe, Germany sity-dependent growth in a mermithid nematode parasitic in beach hoppers. J Helminth 76:65-70

Santos R (1995) Size structure and inequality in a commercial stand of the seaweed Gelidium sesquipedale. Mar Ecol Prog Ser 119:253-263

Steingrímsson SO, Grant JWA (1999) Allometry of territory size and metabolic rate as predictors of self-thinning in young-of-year Atlantic salmon. J Anim Ecol 68:17-26

Steele JH, Edwards RRC (1970) The ecology of O-group plaice and common dabs in Loch Ewe. IV. Dynamics of the plaice and dab populations. J Exp Mar Biol Ecol 4:174-187

van der Veer HW, Witte JIJ (1993) The 'maximum growth/ optimal food condition' hypothesis: a test for 0-group plaice Pleuronectes platessa in the Dutch Wadden Sea. Mar Ecol Prog Ser 101:81-90

van der Veer HW, Berghahn R, Rijnsdorp AD (1994) Impact of juvenile growth on recruitment in flatfish. Neth J Sea Res 32:153-173

van der Veer HW, Bies B, Witte JIJ (2000) Selective growth and mortality of juvenile 0-group plaice Pleuronectes platessa in the Dutch Wadden Sea: a consequence of irreversible non-genetic adaptation during early pelagic life. Mar Ecol Prog Ser 197:273-283

Weiner J, Solbrig OT (1984) The meaning and measurement of size hierarchies in plant populations. Oecologia 61 $334-336$

Wennhage H, Gibson RN, Robb L (1997) The use of drop traps to estimate the efficiency of 2 beam trawls commonly used for sampling juvenile flatfishes. J Fish Biol 51:441-445

Submitted: November 4, 2005; Accepted: February 19, 2007 Proofs received from author(s): July 25, 2007 